\title{
Endoscopic septotomy as a treatment for leaks after sleeve gastrectomy
}

\author{
Meeting presentations: Digestive Disease Week 2019
}

\section{()(1) $\odot$}

Authors

Ramon Diaz, Leonard K. Welsh, Juan Esteban Perez, Andres Narvaez, Gerardo Davalos, Dana Portenier, A. Daniel Guerron

Institution

Division of Minimally Invasive Surgery, Metabolic and Weight Loss Surgery, Department of Surgery, Duke University Health System, Durham, North Carolina, United States

submitted 4.6.2019

accepted after revision 12.8.2019

\author{
Bibliography \\ DOI https://doi.org/10.1055/a-1027-6888 | \\ Endoscopy International Open 2020; 08: E70-E75 \\ (c) Georg Thieme Verlag KG Stuttgart · New York \\ eISSN 2196-9736
}

Corresponding author

Alfredo D. Guerron, MD, Assistant Professor of Surgery, Duke University, 407 Crutchfield St, Durham NC, USA

27704

Fax: +1-919-470-7028

alfredo.guerron-cruz@duke.edu

\section{ABSTRACT}

Background and study aims Sleeve gastrectomy (LSG) is the most commonly performed bariatric procedure in the world. Leaks are the most feared complications after this procedure. Endoscopic septotomy has been described as a resolution technique that could be useful in the setting of late and chronic leaks. We present our experience in the management of gastric leaks with this advanced endoscopic technique.

Patients and methods Retrospective review of patients who have been admitted to our hospital from January 2016 to December 2018

Results Five patients were found. All had their index surgery in outside hospitals. The average age was 51 years (range 40-69), and four patients were female. Mean time from LSG to leak presentation was 15 days (range $7-25$ ). Mean time from leak presentation to septotomy procedure was 61 days (range $21-110$ ). All patients were treated with sleeve dilatation before septotomy using endoscopic achalasia balloons. Mean procedure time was 79 minutes (range $55-125$ ). Success was achieved in $80 \%$ of patients, and no complications related to the procedure were identified. One patient underwent total gastrectomy for definitive management. Mean follow-up time was 14.25 months (range $6-26$ ), and the average time for fistula closure was 60.25 days.

Conclusion Endoscopic septotomy is safe and effective for management of chronic leaks after LSG. Associated non-selective dilatation may be a crucial step to allow distal patency and axis rectification for appropriate leak closure.

\section{Introduction}

Laparoscopic sleeve gastrectomy (LSG) is the most commonly performed bariatric surgery in the world mainly due to favorable weight loss, comorbidity resolution, and a relatively simple technique [1]. Complications after LSG include leaks, bleeding, and strictures [2]. Leaks have been reported in the range of $1 \%$ to $2.9 \%$ of cases $[3,4]$ and carry considerable morbidity and mortality. A multidisciplinary approach is essential to avoid severe long-term morbidity. Endoscopic procedures are com- monly preferred over more invasive surgical approaches and endoscopic septotomy has been proposed as an effective technique for chronic LSG leak treatment [5]. This relatively new procedure allows for fluid drainage from the abscess cavity into the stomach by dividing the septum that separate the abscess from the gastric lumen, thus equalizing cavity pressures and promoting secretion flow into the gastrointestinal tract. These changes result in eventual abscess cavity collapse and clinical resolution. The aim of this article is to report our experi- 


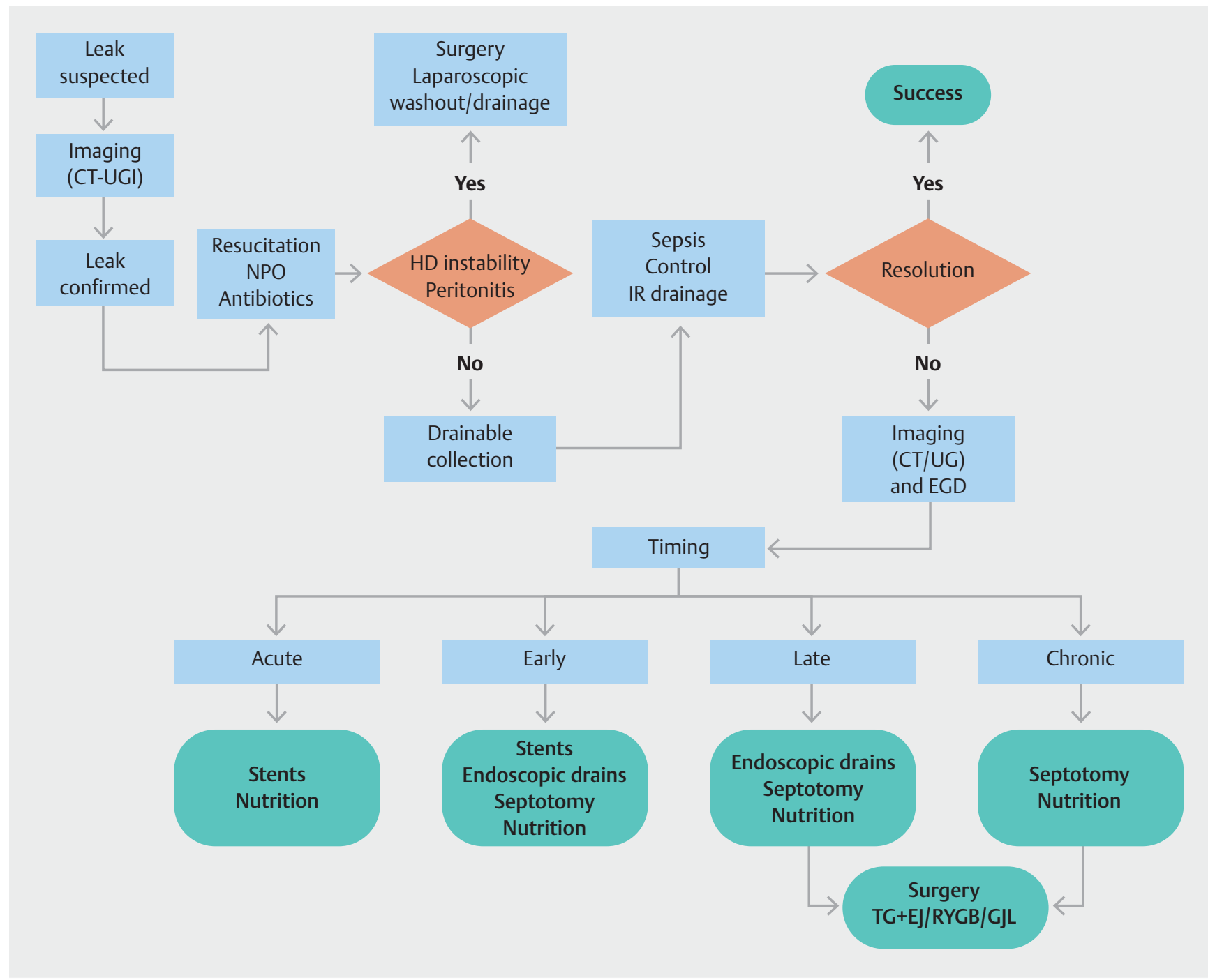

- Fig. 1 Leak management algorithm. CT, computed tomography; UGI, upper gastrointestinal series; NPO: nothing by mouth; HD, hemodynamic; IR, interventional radiology; EGD, esophagogastroduodenoscopy; TG + EJ, total gastrectomy + esophagojejunostomy; RYGB, roux-en-y gastric bypass; GJL, lateral gastrojejunostomy.

ence with this advanced endoscopic technique with patients that have presented leaks after LSG.

\section{Patients and methods}

Institutional Review Board approval was obtained for this retrospective study. Inpatient admission records from January 2016 to December 2018 were queried to identify all patients with a diagnosis of post LSG leak and subsequent endoscopic septotomy. Patients were diagnosed according to symptoms, upper gastrointestinal contrast studies, and computed tomography (CT scan). Our algorithm for approaching suspected leaks after LSG is detailed in > Fig. 1.

\section{Technique description}

As a precaution, we prefer to perform the operation in a full operating room under general anesthesia rather than an endoscopy suite. The patient is positioned supine and a front-viewing endoscope with a disposable distal attachment is used to intubate the esophagus in the standard fashion. A complete survey of the anatomy must be accomplished to evaluate the entire stomach in order to rule out distal strictures or axial deviation. The relationship of the leak orifice to the gastroesophageal junction (GEJ) is determined and documented. Previous imaging studies should be available to compare with the endoscopic findings for confirmation of anatomy and location of the leak. We routinely performed sleeve dilation to address any sleeve axis deviation and treat any possible strictures. Dilation is performed using a $30 \mathrm{~mm}$ achalasia balloon, insufflated to a pressure of 15 psi for 1 minute, and repeated on three occasions. The abscess cavity is then inspected and entered, if possible, for thorough irrigation. Loose tissue fragments should be removed and aspirated as needed carefully to minimize contamination while allowing for removal of necrotic tissue and any foreign bodies. A division of the septum dividing the gastric lumen and the abscess cavity is carried out using a Triangle Tip 

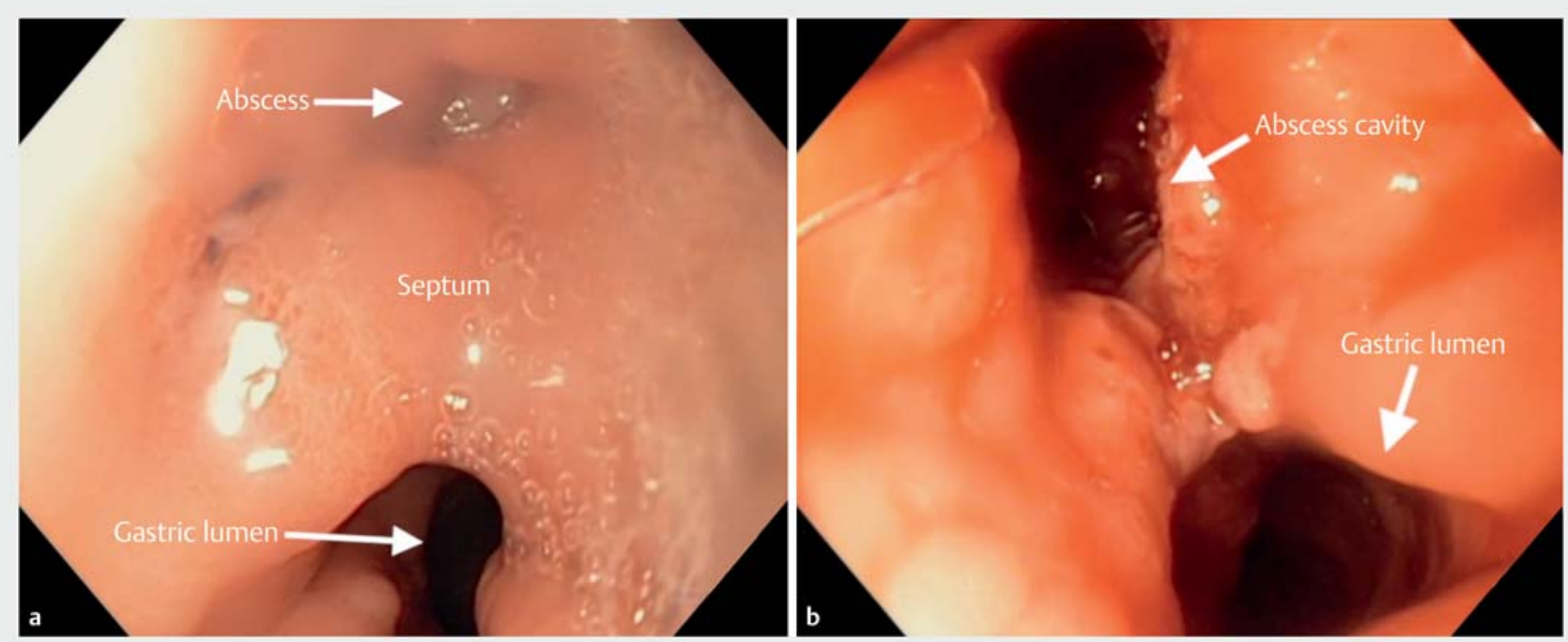

- Fig. 2 Endoscopic images of the abscess cavity separated from the gastric lumen by a a fibrous septum, pre-septotomy procedure and b post-septotomy procedure.

Knife (Olympus, Japan) and electrosurgical energy. Division of the septum is considered complete when the entire abscess cavity communicates with the gastric lumen, thus allowing drainage of secretion into the lumen of the stomach. ( $\mathbf{F i g . 2}$ An overview and technical description of the procedure is included for reference.

\section{Nutritional support}

Nutritional support in patients following an endoscopic septotomy procedure consists of TPN supplementation and advancing oral feeding as tolerated by the patient. This approach does not differ in patients with early, late or chronic leaks, as the septotomy is only performed when there is a well-defined, walled off perigastric abscess cavity, with no communication with the abdominal cavity.

\section{Results}

Five patients meeting inclusion criteria of leak after LSG and treatment with endoscopic septotomy were identified. All had their primary procedures performed at an outside hospital. Previous attempts at leak closure (surgical washout, drain placement, stents or over-the-scope clips placement) were unsuccessful. Three patients had reoperations and drain placement (one laparotomy and two laparoscopies), and two had percutaneous abscess drainage prior to transfer. Mean patient age was 51 years (range 40-69), mean body mass index at the time of septotomy was $40.5 \mathrm{~kg} / \mathrm{m}^{2}$ (range $30.8-50.7$ ), and four patients were female. All patients presented due to abdominal pain. Mean time from LSG to leak presentation was 15 days (range 7-25), and all leaks were located in the upper third of the sleeve. Mean time from leak presentation to septotomy procedure was 61 days (range 21-110). Two patients were found to have a stricture at time of endoscopy; however, all pa- tients were treated with sleeve dilation, with a particular emphasis on the incisura angularis, before septotomy using achalasia balloons. Mean operative time was 79 minutes (range 55125). No procedure-related morbidity or mortality occurred; however, one patient required repeat septotomy due to poor clinical improvement. Despite repeated intervention, the patient experienced treatment failure, ultimately resulting in total gastrectomy with esophagojejunostomy for definitive management. Mean follow-up for the remaining four patients was 14.25 months (range 6-26), and the average time for success (defined as fistula closure on endoscopic visualization) was 60.25 days (range 34-82) (> Fig. 3). Postoperative upper gastrointestinal series and computed tomography scans were used to confirm leak closure. At the time of reported followup, patient weight loss was not affected. All patients continued to lose weight as expected following a LSG. Patient data are further included in $>$ Table 1.

\section{Discussion}

Many factors have been associated with increased risk of leak after LSG [6]. Likewise, leaks can be classified according to the time of presentation as acute (within 7 days), early (within 1-6 weeks), late (after 6 weeks), and chronic (after 12 weeks) [7]. Treatment is primarily based on this classification. A systematic review, which included 4888 patients, described that $79 \%$ of leaks after LSG occurred after hospital discharge, more than ten days after index surgery [4]. In our cohort, all the patients were initially treated at the hospital where the index operation occurred, with either surgical or percutaneous drainage, stenting, and broad-spectrum antibiotic therapy. Although no standardized protocol has been adopted, there is consensus regarding the need to control leakage, establish drainage of the abscess cavity, and promote closure of the fistula. Non-opera- 


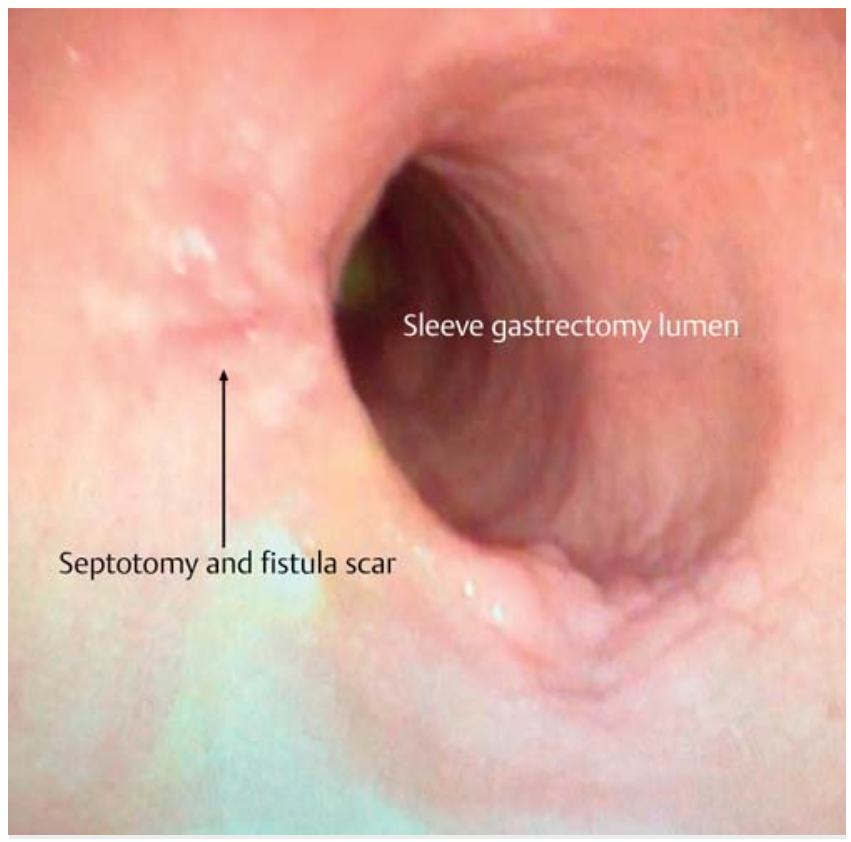

- Fig. 3 Endoscopic septotomy result after long-term follow-up (24 months).

tive management for chronic fistulas should be offered whenever possible. Our group only resorts to surgery for patients in whom all endoscopic options have been exhausted. Moreover, leak treatment must also include optimal antibiotic therapy, nutritional support, and adequate drainage.

Endoscopic stents have been proven an effective treatment option for acute or early leaks with success rates of 84-94\% [8]. Most of these devices are covered or partially covered metal and plastic stents designed for use in the esophagus and colon and repurposed for use in gastric leak treatment. Migration has been reported up to $60 \%$ and can result in severe morbidity [ 9 , 10]. Mega stents have also been reported as an effective option for leak with the advantage that they can exclude the entire staple line [11]. Specifically designed bariatric stent can also address migration, but these are not currently available in the United States $[12,13]$. Stenting of chronic leaks is much less effective with varied success rates ranging from $19 \%$ to $81 \%[14$, $15]$. Endoscopic closure of leaks with over-the-scope clip sys- tems can be successful up to $86 \%$ of the time, but success rates are much lower in cases of chronic leaks due to difficulty approximating fibrous tissue [16]. We believe that the same limitations apply to novel endoscopic suturing devices. Ultimately, when endoscopic modalities have failed, revisional surgery with conversion to gastric bypass, gastrojejunal lateral anastomosis, or total gastrectomy with esophagojejunostomy may be warranted [17]. Surgical interventions are not without associated complications and sequelae that may introduce increased risks over potential benefits [17-19].

Intraluminal pressure of the stomach increases after LSG [20] and can lead to a pressure gradient favoring flow through the fistula or leak into the abscess cavity, thus leading to a vicious cycle further preventing closure. Septum division allows for equalization of stomach and abscess cavity pressures, which when combined with aggressive sleeve dilatation, flow can be redirected towards the distal portion of the sleeve [21]. Endoscopic internal drainage has been proven effective in a prior series using double plastic pigtail catheters to connect the abscess cavity and the lumen of the stomach [22]. Endoscopic septotomy for leaks after LSG was first described by Campos et al. in 2007, borrowing from diverticulotomy principles used in treatment of Zenker's diverticulae [23,24]. This technique has been further applied to treatment of leaks after gastric bypass and biliopancreatic diversion in addition to LSG [25].

In this report, we show our experience with endoscopic septotomy for treatment of patients with late and chronic leaks after LSG, as well as one early leak, with a success of $80 \%(4 / 5)$. Septotomy was an option for the patient with an early leak because of a well-defined abscess wall, even though it was early in the clinical course. One patient did not respond to endoscopic treatment and needed a total gastrectomy for definitive management of the leak. In this patient, we believe that endoscopic septotomy failed because of inability to relieve the distal sleeve stricture, despite multiple attempts at dilation using an achalasia balloon. Without resolving the distal stricture, intraluminal sleeve pressures remained high, which did not favor abscess drainage into the cavity and eventual resolution. Lima [26] described his technique in 2014, using endoscopic septotomy for the treatment of a female patient 30 days after the LSG with complete resolution of the leak at 30-day follow-up. Moreover, the author discussed use of septotomy in 10 previous patients with leak resolution no later than 60 days. Baretta et al [25] per-

- Table 1 Cohort of patients who underwent septotomy at our institution.

\begin{tabular}{|c|c|c|c|c|c|c|c|c|c|}
\hline Gender & $\begin{array}{l}\text { Age } \\
\text { (year) }\end{array}$ & $\begin{array}{l}\text { Time to leak } \\
\text { (days) }\end{array}$ & $\begin{array}{l}\text { Leak loca- } \\
\text { tion }\end{array}$ & $\begin{array}{l}\text { Stric- } \\
\text { ture }\end{array}$ & $\begin{array}{l}\text { Septot- } \\
\text { omy }\end{array}$ & $\begin{array}{l}\text { Operative } \\
\text { time (min) }\end{array}$ & $\begin{array}{l}\text { Morbid- } \\
\text { ity }\end{array}$ & Mortality & $\begin{array}{l}\text { Additional } \\
\text { procedure }\end{array}$ \\
\hline Female & 43 & 25 & Upper third & No & Yes & 71 & No & No & 0 \\
\hline Female & 42 & 11 & Upper third & Yes & Yes & 79 & No & No & 0 \\
\hline Female & 40 & 19 & Upper third & Yes & Yes & 65 & No & No & 0 \\
\hline Female $^{1}$ & 69 & 7 & Upper third & No & Yes & 55 & No & No & Re-septotomy \\
\hline Male & 62 & 14 & Upper third & No & Yes & 125 & No & No & 0 \\
\hline
\end{tabular}


- Table 2 Largest publications related to septotomy as a treatment for leaks after LSG.

\begin{tabular}{|c|c|c|c|c|c|c|}
\hline Author (year) & $\begin{array}{l}\text { Number of } \\
\text { patients }\end{array}$ & Cutting device & $\begin{array}{l}\text { Dilata- } \\
\text { tion }\end{array}$ & $\begin{array}{l}\text { Number of ses- } \\
\text { sions (mean) }\end{array}$ & $\begin{array}{l}\text { Time to septotomy } \\
\text { from leak (days) }\end{array}$ & $\begin{array}{l}\text { Time to heal } \\
\text { (days) }\end{array}$ \\
\hline Baretta $(2015)^{1}[25]$ & 9 & Needle-Knife or APC & 7 & 1.81 & NR & 24.67 \\
\hline Mahadev (2017) [28] & 9 & $\begin{array}{l}\text { Needle-Knife (3) and } \\
\text { APC (6) }\end{array}$ & 5 & 2.3 & 60.2 & NR \\
\hline Shnell (2017) [29] & $\begin{array}{l}10 \text { ( } 6 \text { late and } 4 \\
\text { chronic) }\end{array}$ & $\mathrm{APC}(8)$ and BFD (2) & 8 & 5 & NR & NR \\
\hline
\end{tabular}

formed septotomies in nine patients after LSG, being successful in $100 \%$ with just one perforation due to concomitant dilatation. In 2016, Campos et al [27] defined their technique using argon plasma coagulation and Needle-Knife (Boston Scientific, Massachusetts, United States) for septum section in a female patient 60 days after LSG with resolution after two sessions. Mahadev et al [28] showed one of the most significant experiences in a multicenter study completed in the United States. The authors performed nine septotomies, using either NeedleKnife or argon plasma beam, with $66 \%$ of resolution, and no adverse events related to the septotomy. Of note, this is the only publication which reports average procedure duration time of 87.2 minutes, similar to our average time of 79 minutes. Shnell et al [29] reported 10 patients with late/chronic leaks after LSG. Septotomy was performed using argon plasma coagulation plus balloon dilatation in eight patients. The two remaining patients were treated using through-the-scope dilatation of the fistula up to $20 \mathrm{~mm}$ to achieve septum obliteration with success. Authors did not have any significant complications or adverse events related to the septotomy procedure. Details of the three largest series are summarized in $>$ Table 2 .

Currently, only argon plasma and Needle-Knife have been reported as cutting devices to perform septotomy, and due to inflammation, the septum is prone to bleeding. Endoscopists should use the device and hemostatic technology with which they feel most comfortable. In our experience, we prefer to use the Triangle Tip Knife instead of argon plasma and we have not had experienced any bleeding issues [5]. Of note, other authors perform selective dilatation of the sleeve only in cases where a stricture is identified. In our cohort, only two strictures were endoscopically confirmed, but still dilate all our cases in order to achieve maximum distal gastric patency for optimal drainage. This aggressive strategy may partly contribute to our $80 \%$ single-session success rate.

The limitations of this study include its small sample size and its retrospective methodology. Owing to the current low incidence of leak after LSG, developing prospective randomizedcontrolled studies could be challenging to design and carry out.

\section{Conclusion}

Endoscopic septotomy is a practical and effective approach for patients with early, late, and chronic leaks after LSG when the perigastric cavity and fistulous tract are well established. Endoscopic interventions may lead to avoiding high morbidity surgical procedures. Aggressive endoscopic sleeve dilation allows for improved drainage of the cavity and a greater chance for success.

\section{Competing interests}

Dr. Portenier reports grants and personal fees from Medtronic, grants from Levita, grants from Gore, personal fees from Intuitive, outside the submitted work. Dr. Guerron reports personal fees from Levita, personal fees from Gore, personal fees from Medtronic, outside the submitted work.

\section{References}

[1] Ozsoy Z, Demir E. Which bariatric procedure is the most popular in the world? a bibliometric comparison Obes Surg 2018; 28: 23392352

[2] Sarkhosh K, Birch DW, Sharma A et al. Complications associated with laparoscopic sleeve gastrectomy for morbid obesity: a surgeon's guide. Can J Surg 2013; 56: 347-352

[3] Rosenthal R], Diaz AA, Arvidsson D et al. International Sleeve Gastrectomy Expert Panel Consensus Statement: best practice guidelines based on experience of $>12,000$ cases. Surg Obes Relat Dis 2012; 8: 8-19

[4] Aurora AR, Khaitan L, Saber AA. Sleeve gastrectomy and the risk of leak: a systematic analysis of 4,888 patients. Surg Endosc 2012; 26: 1509-1515

[5] Ortega CB, Guerron AD, Portenier D. Endoscopic abscess septotomy: a less invasive approach for the treatment of sleeve gastrectomy leaks. J Laparoendosc Adv Surg Tech A 2018; 28: 859-863

[6] Benedix F, Benedix DD, Knoll C et al. Are there risk factors that increase the rate of staple line leakage in patients undergoing primary sleeve gastrectomy for morbid obesity? Obes Surg 2014; 24: 16101616

[7] Rosenthal RJ, Diaz AA. International Sleeve Gastrectomy Expert P. et al. International Sleeve Gastrectomy Expert Panel Consensus State- 
ment: best practice guidelines based on experience of $>12,000$ cases. Surg Obes Relat Dis 2012; 8: 8-19

[8] Walsh C, Karmali S. Endoscopic management of bariatric complications: A review and update. World J Gastrointest Endosc 2015; 7: 518 523

[9] Bege T, Emungania O, Vitton $V$ et al. An endoscopic strategy for management of anastomotic complications from bariatric surgery: a prospective study. Gastrointest Endosc 2011; 73: 238-244

[10] Karagul S, Yagci MA, Ara C et al. Small bowel perforation due to a migrated esophageal stent: Report of a rare case and review of the literature. Int J Surg Case Rep 2015; 11: 113-116

[11] Klimczak T, Klimczak J, Szewczyk T et al. Endoscopic treatment of leaks after laparoscopic sleeve gastrectomy using MEGA esophageal covered stents. Surg Endosc 2018; 32: 2038-2045

[12] Southwell T, Lim TH, Ogra R. Endoscopic therapy for treatment of staple line leaks post-laparoscopic sleeve gastrectomy (LSG): experience from a large bariatric surgery centre in New Zealand. Obes Surg 2016; 26: 1155-1162

[13] van Wezenbeek MR, de Milliano MM, Nienhuijs SW et al. A specifically designed stent for anastomotic leaks after bariatric surgery: experiences in a tertiary referral hospital. Obes Surg 2016; 26: 1875-1880

[14] Eisendrath P, Cremer M, Himpens J et al. Endotherapy including temporary stenting of fistulas of the upper gastrointestinal tract after laparoscopic bariatric surgery. Endoscopy 2007; 39: 625-630

[15] Puig CA, Waked TM, Baron TH et al. The role of endoscopic stents in the management of chronic anastomotic and staple line leaks and chronic strictures after bariatric surgery. Surg Obes Relat Dis 2014; 10: 613-617

[16] Shoar S, Poliakin L, Khorgami Z et al. Efficacy and safety of the overthe-scope clip (OTSC) system in the management of leak and fistula after laparoscopic sleeve gastrectomy: a systematic review. Obes Surg 2017; 27: 2410-2418

[17] Nedelcu AM, Skalli M, Deneve E et al. Surgical management of chronic fistula after sleeve gastrectomy. Surg Obes Relat Dis 2013; 9: 879884
[18] Ramos AC, Ramos MG, Campos JM et al. Laparoscopic total gastrectomy as an alternative treatment to postsleeve chronic fistula. Surg Obes Relat Dis 2015; 11: 552-556

[19] Sakran N, Assalia A, Keidar A et al. Gastrobronchial fistula as a complication of bariatric surgery: a series of 6 cases. Obes Facts 2012; 5: 538-545

[20] Yehoshua RT, Eidelman LA, Stein M et al. Laparoscopic sleeve gastrectomy-volume and pressure assessment. Obes Surg 2008; 18: 1083-1088

[21] Guerron AD, Ortega CB, Portenier D. Endoscopic abscess septotomy for management of sleeve gastrectomy leak. Obes Surg 2017; 27: 2672-2674

[22] Donatelli G, Ferretti S, Vergeau BM et al. Endoscopic internal drainage with enteral nutrition (EDEN) for treatment of leaks following sleeve gastrectomy. Obes Surg 2014; 24: 1400-1407

[23] Adams J, Sheppard B, Andersen P et al. Zenker's diverticulostomy with cricopharyngeal myotomy: the endoscopic approach. Surg Endosc 2001; 15: 34-37

[24] Campos JM, Siqueira LT, Ferraz AA et al. Gastrobronchial fistula after obesity surgery. J Am Coll Surg 2007; 204: 711

[25] Baretta G, Campos ], Correia S et al. Bariatric postoperative fistula: a life-saving endoscopic procedure. Surg Endosc 2015; 29: 1714-1720

[26] de Lima JH. Endoscopic treatment of post vertical gastrectomy fistula: septotomy associated with air expansion of incisura angularis. Arq Bras Cir Dig 2014; 27: 80-81

[27] Campos JM, Ferreira FC, Teixeira AF et al. Septotomy and balloon dilation to treat chronic leak after sleeve gastrectomy: technical principles. Obes Surg 2016; 26: 1992-1993

[28] Mahadev S, Kumbhari V, Campos JM et al. Endoscopic septotomy: an effective approach for internal drainage of sleeve gastrectomy-associated collections. Endoscopy 2017; 49: 504-508

[29] Shnell M, Gluck N, Abu-Abeid S et al. Use of endoscopic septotomy for the treatment of late staple-line leaks after laparoscopic sleeve gastrectomy. Endoscopy 2017; 49: 59-63 